Research letter

\title{
Ectopic low-lying implantation pregnancy: analysis of outcomes depending on gestation age
}

\author{
Tatiana B. Makukhina ${ }^{1,2}$, Viktoriia V. Makukhina ${ }^{1}$ \\ ${ }^{1}$ Kuban State Medical University, Krasnodar, Russia \\ ${ }^{2}$ City Clinical Hospital No. 1, Krasnodar, Russia
}

Received 04 January 2018, Revised 6 July 2018, Accepted 11 October 2018

(C) 2018, Makukhina T.B., Makukhina V.V.

(C) 2018, Russian Open Medical Journal

\begin{abstract}
The objective is to define the optimal term of treatment of ectopic low-lying implantation pregnancy (LIP), including cesarean scar pregnancies (CSP) and cervico-isthmic pregnancies (CIP).

Material and Methods - A single-center retrospective study examining the data of 37 patients with CSP and CIP. Gestation age (GA), human chorionic gonadotropin ( $\beta$-HCG) level, ultrasound protocols, outcomes and follow-up were evaluated. The patients were divided into two groups according to their gestation age (GA) calculated from the last menstrual period, i.e.: up to 55 days inclusively $-1^{\text {st }}$ group, 56 days and more $-2^{\text {nd }}$ group.

Results - Significant difference was found in blood loss and repeated invasive procedures (RIP) numbers between the groups ( $p=0.010$ and $\mathrm{p}=0.046$, respectively). $\mathrm{GA}>55$ days increases the risk of RIP for patients with LIP four times $(\mathrm{OR}=4.00,95 \% \mathrm{Cl} 0.99-16.15)$.

Conclusion - Termination of LIP performed in $1^{\text {-st }}$ trimester allows to preserve uterus in all cases. Blood loss and the risk of RIP were significantly lower if LIP termination was performed before $8^{\text {th }}$ gestational week.
\end{abstract}

Keywords: pregnancy loss (ectopic pregnancy), antenatal bleeding, low-lying implantation pregnancy, cesarean scar pregnancy, cervicoisthmic pregnancy

Cite as Makukhina TB, Makukhina VV. Ectopic low-lying implantation pregnancy: analysis of outcomes depending on gestation age. Russian Open Medical Journal 2019; 8: e0208.

Correspondence to Tatiana Makukhina. E-mail: soltatiana@mail.ru.

\section{Introduction}

Rate of non-tubal ectopic pregnancies (EP) ranges from $5.0 \%$ to $10 \%$ from all EPs [1-3] though their overall incidence has been increasing in recent years [4]. Furthermore, non-tubal EPs contribute disproportionately to maternal morbidity and mortality in comparison to tubal EPs [2, 3].

There are no standards for diagnostics and treatment of this pathology [5-9]. Management of non-tubal EP may involve expectancy, medical or surgical treatment, or their combination, minimally invasive radiological approaches depending on EP location and the patient's clinical stability $[2,3,9]$.

Some of these non-tubal pregnancies are characterized by trophoblast invasion in the lower segment of the uterus including previous cesarean scars, cervico-isthmus or cervix. They are similar in incidence rarity but cause life-threatening bleeding.

The number of reported cases of Cesarean scar pregnancy (CSP) has increased in the last 10 years because of the increase in Cesarean sections number and the improvement in ultrasound detection in the first trimester [3, 10-14]. Cervico-isthmic implantation is also viewed as a variation of EP [9, 15-17]. Some authors associate this localization with CSP as pregnancy located below the internal os $[15,17]$. Due to their relative rarity CSPs have proved difficult to study and there is still lack of agreement regarding the most appropriate diagnostic criteria and optimal strategies to treat this condition $[9,10,12,18-20]$. Some specialists affiliate CSP, cervico-isthmic pregnancy (CIP) and cervical pregnancy into "pregnancy in an abnormal location" or "low-lying-implantation ectopic pregnancy" because the low segment is less capable of fibromuscular contraction to control bleeding $[17,21]$. However, this term is not quite appropriate, because livebirth is considered impossible for cervical pregnancy, but is being discussed for CSP and CIP [13, 22].

In recent years the number of reports of livebirth delivery has increased although this situation is always connected with high risk of bleeding and hysterectomy [2, 13, 17, 22-25]. Unfortunately, in clinical practice the majority of clinicians have very limited experience and confidence in the differential diagnosis of this pathology and treatment is at the physicians' discretion [16]. Literature about non-tubal EP has been restricted to small case reports and series, with limited data on optimal treatment protocols [1].

The objective is to define the optimal term of treatment of ectopic low-lying implantation pregnancy (LIP), including CSP and CIP. 


\section{Material and methods}

A single-center retrospective study of 997 consecutive patients with EP of gynecological department of the City Hospital \#1 of Krasnodar (2011-2016 years) found CSP and CIP before 14 gestation weeks in 37 cases (3.7\%). Taking into consideration the similar clinical characteristics and management we unified patients with CSP and CIP into a category of LIP. The diagnosis was based on ultrasound examination (US) data, performed in the hospital and human chorionic gonadotropin ( $\beta$-HCG) level in blood.

Each patient with confirmed LIP gave the informed consent to treatment options, including open surgery, systemic chemotherapy, mini-invasive radiological approaches procedures (uterine artery embolization under X-ray control (UAE), dilatation and curettage/vacuum aspiration under US control (D@C/VA,) local methotrexate (MTX) administration under US control) and their combinations.

US protocols, blood loss, time of $\beta$-HCG level decrease, spotting duration and outcomes were evaluated. We considered the outcomes as successful if no further interventions were required after the procedure, and complicated if any additional interventions were performed. Patients were divided into two groups taking into account gestation age (GA) according to the last menstrual period (LMP) $\left(1^{\text {st }}\right.$ group - GA less 56 days, $n=22 ; 2^{\text {nd }}$ group - GA 56 and more days, $n=15$ ).

The statistical analysis was performed using statistical software (SPSS, Version 18.0). Examination of the form of distribution of signs was carried out using Shapiro-Wilk test. Median and interquartile range were used for description of numerical characteristics of statistical distribution of signs - Me $(L Q, U Q)$. Mean values of quantitative attributes were estimated using the nonparametric Mann-Whitney $U$ test. To determine the statistical significance of differences of observed and expected frequencies of qualitative attributes the chi-square test $\left(\chi^{2}\right)$ was used.

The critical level of significance was defined with a two-tailed test $p<0.05$. Comparison of risk of repeated invasive procedures (RIP) between the groups was performed using the calculation of odds ratio and relative risk factor (RR). To visualize the nature of relation between the variables a scattering diagram was applied.

\section{Results}

According to the retrospective data ultrasound protocols the sensitivity of routine pelvic ultrasound examination for LIP diagnostics amounted to $54 \%$ (prior to hospital admission the diagnosis was confirmed by US in 20 cases: 10 in the $1^{\text {st }}$ group and 10 in the $2^{\text {nd }}$ group). US criteria for CSP (LIP) are well-known: location of "empty" uterus and "empty" cervical canal; visualization of gestation sac/trophoblast in scar/isthmus; myometrial thinning of anterior wall of uterus (1-3 mm); gestation sac located in the "niche" surrounded by myometrium/fibrose tissue separated from cavum uterus; hypervascular pattern with trophoblastic blood flow into scar with positive test for $\beta$-HCG; negative "sliding-sign"; placental bulge, placental lacunae $[13,15,16,26]$.

Most of these criteria were absent or misinterpreted in medical reports. Eight patients $(21.6 \%)$ were admitted with bleeding after D@C/VA performed in other hospitals while LIP was overlooked. All of them needed RIP for the purpose of haemostasis. 2 among 8 these patients had GA less than 56 days, and 6 patients - 56 days and more. In all cases RIP were performed: with less 56 days GA - in 1 case D@C under US control with systemic MTX administration; in 1 case $\mathrm{D} @ \mathrm{C}+\mathrm{UAE}+\mathrm{MTX}$; with 56 days and more GA - in 2 cases D@C under US-control with systemic MTX administration, in 4 cases $D @ C+U A E+M T X$ were carried out.

Analyses of all examined LIP cases discovered that D@C/VA as a self-sustained treatment method was efficient only in cases where GA was less than 8 weeks (up to 55 days from LMP) (table 1). For patients with LIP, whose GA overpassed 55 days from LMP, all attempts of D@C/VA resulted in repeated interventions (table 1). Out of 6 cases, which required RIP in the $1^{\text {st }}$ group: in one case UAE was carried out two months later in connection with profuse bleeding due to arterio-venous malformation, despite of decrease in $\beta$-HCG up to the subliminal level. As a whole, without considering the methods of treatment, the difference in the necessity of RIP between the groups was significant $\left(\chi^{2}=3.96\right.$, $\mathrm{p}=0.046)$ (Table 1).

Analysis of treatment and outcomes based on GA demonstrates significant difference in blood loss and numbers of RIP between the groups with GA less than 8 weeks and more than that (Table 2).

Scattering diagram was used for graphical visualization of relation between the observation period before decrease in $\beta$ HCG and blood loss. Points' position demonstrates that the group with gestational age of 8 weeks and more has a wider field of distribution than the other group (Figure 1).

For the group with $\mathrm{GA}>55$ days Relative Risk (RR) of RIP was 2.2 times higher, than in the group with $G A \leq 55(6 / 22$ vs 9/15; RR: $2.2,95 \% \mathrm{Cl} 0.991-4.885$ ) (Table 3). Odd ratio calculation showed that the factor of GA>55 increases the risk of RIP four times (9/6 vs 6/16, $\left.\chi^{2}=3.96, p=0.046 ; \mathrm{OR}=4.00,95 \% \mathrm{Cl} 0.99-16.15\right)$ (Table 3).

\section{Discussion}

Estimated incidence of CSP is 1.5 per 10,000 maternities [19]. Despite rarity of LIP diagnostics, difficulties and morbidity present the actuality of this problem. Ectopic cesarean scar pregnancy needs to be differentiated from normal but low intrauterine pregnancy, abortion in progress, true cervical pregnancy $[7,12$, $14,16]$. There are lots of publications focused on early diagnostic criteria of cesarean scar pregnancy because treatment during first trimester in most cases allowed to preserve fertility $[9,11,14,16$, 18-20, 27]. Unrecognized or misdiagnosed CSPs treated with inadequate procedures may lead to severe and sometime uncontrollable vaginal bleeding and hysterectomy.

The clinical diagnosis without the visualization methods is extremely difficult. Unfortunately, our study shows insufficient level of knowledge about diagnostic criteria of LIP among ultrasound specialists. Without standard compulsive protocol, we have a high number of false-negative conclusions, which caused prolongation of diagnostic time and treatment with repeated invasive procedure. In cases when LIP is missed in first trimester, the probability of fertility loss increases multi-fold. Four patients with LIP prolonged for more than 14 weeks not included in analysis in our study had profuse bleeding $(600-5,000 \mathrm{ml})$ and fetal demise in all cases. Hysterectomy was performed in two cases. 
Table 1. Method of LIP treatment in relation to GA

\begin{tabular}{|c|c|c|c|c|}
\hline \multirow{4}{*}{$\begin{array}{l}\text { Method of } \\
\text { treatment } \\
\text { D@C/VA }\end{array}$} & \multicolumn{2}{|c|}{$\begin{array}{c}\text { Group } 1 \\
\text { GA, less } 56 \text { days, }(n=22)\end{array}$} & \multicolumn{2}{|c|}{$\begin{array}{c}\text { Group 2 } \\
\text { GA, } 56 \text { and more days, }(n=15)\end{array}$} \\
\hline & \multicolumn{2}{|c|}{$\mathrm{n}=9$} & \multicolumn{2}{|c|}{$n=6$} \\
\hline & \multirow[t]{2}{*}{$\mathrm{NC}, \mathrm{n}=6$} & $\mathrm{RIP}, \mathrm{n}=6$ & \multirow[t]{2}{*}{$\mathrm{NC}, \mathrm{n}=0$} & RIP, $n=6$ \\
\hline & & $\begin{array}{l}\text { Methods: } \\
\text { UAE, } n=1 ; D @ C / V A+M T X, n=1 ; \\
D C / V A+M T X+U A E, n=1 ;\end{array}$ & & $\begin{array}{c}\text { Methods: } \\
D @ C / V A+M T X+U A E, n=4 ; \\
D @ C / V A+M T X, n=2\end{array}$ \\
\hline \multirow[t]{2}{*}{$\mathrm{D} @ \mathrm{C} / \mathrm{VA}+\mathrm{UAE}$} & \multicolumn{2}{|c|}{$n=1$} & \multicolumn{2}{|r|}{$n=1$} \\
\hline & NC, $n=1$ & RIP, $n=0$ & NC, $n=1$ & RIP, $n=0$ \\
\hline D@C/VA & \multicolumn{2}{|c|}{$n=4$} & \multicolumn{2}{|r|}{$n=2$} \\
\hline$+\mathrm{MTX}$ & $\begin{array}{l}\mathrm{NC}, \\
\mathrm{n}=2\end{array}$ & $\begin{array}{c}\text { RIP, } n=2 \\
\text { Methods: } \\
\text { D@C/VA, } n=2\end{array}$ & $\mathrm{NC}, \mathrm{n}=2$ & RIP, $n=0$ \\
\hline D@C/VA & \multicolumn{2}{|c|}{$n=0$} & \multicolumn{2}{|r|}{$n=1$} \\
\hline$+\mathrm{MTX}+\mathrm{UAE}$ & NC, $n=0$ & $\mathrm{RIP}, \mathrm{n}=0$ & $\mathrm{NC}, \mathrm{n}=1$ & $\mathrm{RIP}, \mathrm{n}=0$ \\
\hline \multirow[t]{3}{*}{ MTX } & \multicolumn{2}{|c|}{$n=8$} & \multicolumn{2}{|r|}{$n=5$} \\
\hline & \multirow[t]{2}{*}{ NC, $n=7$} & $R I P, n=1$ & \multirow[t]{2}{*}{$\mathrm{NC}, \mathrm{n}=2$} & $R I P, n=3$ \\
\hline & & $\begin{array}{l}\text { Method: } \\
\text { Local MTX } \\
\text { administration, } \mathrm{n}=1\end{array}$ & & $\begin{array}{l}\text { Methods: } \\
\text { Local MTX administration, } n=1 ; \\
\text { D@C/VA, } n=2\end{array}$ \\
\hline Total & NC, $n=16$ & *RIP, $n=6$ & NC, $n=6$ & $* R I P, n=9$ \\
\hline
\end{tabular}

* Significance of differences, $\chi^{2}, p ;$ NC - No complications

Table 2. Outcomes of LIP in relation to GA

\begin{tabular}{|c|c|c|c|c|}
\hline GA, days from $L M P$ (weeks), $n$ & $\begin{array}{c}\text { Blood loss, } \mathrm{ml} \\
\text { Me }(25 \%-75 \%)\end{array}$ & $\begin{array}{l}\text { Time of B-HCG level decrease, days } \\
\text { Me (25\%-75\%) }\end{array}$ & $\begin{array}{l}\text { Spotting, days } \\
\text { Me }(25 \%-75 \%)\end{array}$ & $\begin{array}{l}R I P, \\
n(\%)\end{array}$ \\
\hline 55 days and less (5-7 weeks); $n=22$ & $60(50-85)$ & $21(17-33.5)$ & $30,1 \pm 11.1$ & $6(27.3)$ \\
\hline From 56 to 84 days ( $8-12$ weeks); $n=15$ & $120(60-800)$ & $38(22-64)$ & $42.7 \pm 18.1$ & $9(60.0)$ \\
\hline Significance of differences & $\mathrm{U}=47,5 ; p=0,010$ & $U=113.0 ; p=0.113$ & $U=53.0 ; p=0.200$ & $\chi 2=396 ; p=0.046$ \\
\hline
\end{tabular}

Table 3. Risk evaluation of RIP depends on GA

\begin{tabular}{lccr}
\hline & Value & \multicolumn{2}{c}{ Cl 95\% } \\
& & lower & upper \\
\hline Odd ratio for GA (56 days and more/less) & 4.000 & 0.991 & 16.148 \\
Relative risk for cohort "RIP performed" & 2.200 & 0.991 & 4.885 \\
Relative risk for cohort "no RIP" & 0.550 & 0.281 & 1.075 \\
Number of observations & 37 & & \\
\hline
\end{tabular}

$\mathrm{Cl}$, confidence interval.

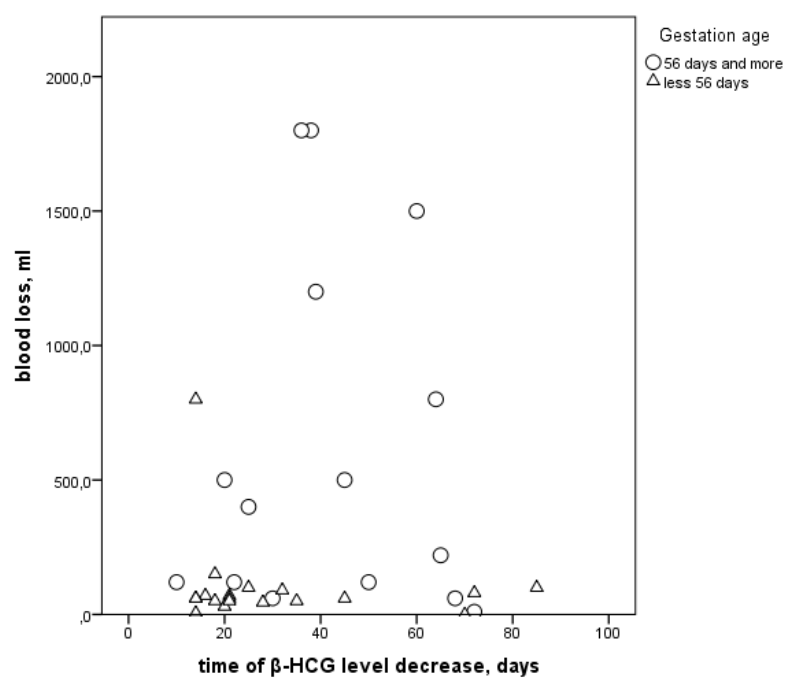

Figure 1. Relation between the observation period before decrease in $\beta$ HCG and blood loss
Recent studies confirmed that chorion invasion is not necessarily connected with the cesarean scar. The fibrous scar tissue may develop after other uterine surgeries such as dilation and curettage, myomectomy, metroplasty, hysteroscopy, and manual placenta removal. Implantation disorders, such as placenta accreta, increta or percreta, are explained by the absence of protective decidua basalis, which results in trophoblastic invasion $[11,22,27,28]$. However, CSP is more aggressive in its behaviour than placenta praevia accreta because of its early invasion in the myometrium $[6,27]$.

In series of our observations, eight patients had LIP with cervico-isthmic localization without cesarean section. Seven of them had D@C (abortions) before and one underwent adhesiolysis (for Asherman syndrome). That is why we prefer to use term "ectopic low-lying implantation pregnancy", as "cesarean scar pregnancy" does not take into account the cases of isthmic localization pregnancy and decreases specialists' alertness for this pathology.

The diagnosis of Cesarean scar pregnancy is being made increasingly in asymptomatic or minimally symptomatic women with wanted live pregnancies attending for first-trimester dating or reassurance scans; in these women, decisions regarding management are much harder to make [5]. The main difficulty in counseling of women diagnosed with asymptomatic scar pregnancy is lack of our understanding of the natural history of the condition and our inability to predict the likelihood of different outcomes [5].

Due to the relative rarity of the condition no universal treatment guidelines for management of CSP have been published up to now $[9,18,20]$. Fourteen women (54\%) with CSP were 
managed conservatively, as there was evidence of a spontaneous resolution [20]. In over study the success rates of expectant management were 43\% (9/21) [19]. Complication rates range, however, from $10 \%$ to $62 \%[9,12,14,19]$. These cases require more complex and more expensive methods of treatment. Discharge from care (median number of days) was 82 (range 37174) with expectant, 21 (range 10-31) with medical and 11 (range 4-49) with surgical management [19]. In a series of 10 patients with CSP with fetal cardiac activity who elected for expectant management $80 \%$ required hysterectomies [25]. Early diagnosis allows to avoid uterine rupture and haemorrhage, thus preserving the uterus and fertility. Some authors believe that expectant management should not be recommended [18]

There is no common point of view on the optimal diagnostic term. Timor-Tritsch IE [14] investigated diagnostic worth of the center of gestation sac location till 10 gestation weeks for CSP diagnostic. El-Refaey $\mathrm{H}$ in comments to article $\mathrm{CH}$ Comstock [28] indicated that "As the gestational sac becomes larger it fills the whole cavity and it encroaches on the niche of the previous cesarean section scar. Identification of the original implantation site will therefore become harder". He proposes that all women who have had previous cesarean sections should have a transvaginal scan examination between 6 and 8 weeks of gestation in any subsequent pregnancy. Cali G [26] also used a 6-8 gestation weeks period for differential diagnosis. But Zosmer $N$ [13] thought that the assessment of ongoing pregnancies implanted in CS scars is probably best performed not earlier than 7 and 9 weeks' gestation.

In addition, it is psychologically more difficult for patients with prolonged gestation age to agree to the pregnancy termination.

Most studies focused on comparative evaluation of results of different methods of CSP treatment $[9,19,20]$. However, due to the rarity of this pathology statistical power of the majority of the studies is not sufficient for reliable results. It is impossible to compare the influence of the method of treatment on the outcome as part of this study due to the small number of patients and variety of treatment protocols. The low number of cases can be considered the main limitation of this study. Some studies demonstrate the connection between the gestation age at the moment of pregnancy termination and the complication rates for specific treatment methods without providing any general guidelines specifying preferable gestation age for treatment [9].

Our study confirmed the increasing frequency of complications such as intraoperative blood loss, numbers of repeated invasive procedures for LIP terminated after 8 weeks of gestation regardless of the method of treatment.

We did not investigate subsequent fertility of patients in this study. However, three patients were readmitted to our Hospital with uterine pregnancies in period from 6 to 12 months after the treatment of LIP ( $n=1$ after VA, $n=2$ after VA+MTX). Our experience of UAE use was successful in all cases with excellent bleeding control. There were no registered complications connected with our procedures, but in 3 patients wishing to conceive pregnancies did not happen afterwards. There were no repeated cases of LIP among our patients.

Taking into account the high risk of serious complications of LIP, including loss of reproductive function and potential growth of this pathology due to increase in uterus surgery among premenopausal women, we need to detect LIP earlier. An early diagnosis and a proper management are fundamental to prevent maternal complications $[9,20]$.

An early detection requires a high index of suspicion, strict diagnostic criteria, and properly trained, experienced sonographers [20]. In our opinion it is necessary to conduct the screening of risk group with simple and reproducible tests and standard protocol (in a similar way to chromosomal anomaly screening) (before 8 gestation weeks) during and individual risk calculation for asymptomatic women with previous uterus surgery.

Patients with high individual risk of LIP and following abnormally invasive placenta must have expert counselling with detailed information about maternal and fetal risks given, prognosis for fertility preservation in cases of pregnancy prolongation or termination. Prolongation of LIP is possible in certain cases of patient informingly refusing pregnancy termination.

A small number of observations stipulated by rare detectability of this pathology should be attributed to limitation in design of the performed study. Nonparametric criteria only were used for statistical analysis, because the variables did not follow the normal distribution. Due to rarity of this pathology, we need multicentral investigation of prognosis, management and recurrence risk for LIP for recommendation establishment.

\section{Conclusion}

Termination of CSP and CIP performed in first trimester allows to preserve uterus in all cases. Blood loss and repeated invasive procedures numbers are lower when termination of LIP is performed before 8 gestation weeks.

\section{Conflict of interest}

No author has any potential conflict of interest.

\section{Funding}

This study was not funded by any company and does not promote anybody's interests.

\section{Ethical approval}

All procedures performed in studies involving human participants were in accordance with the ethical standards of the institutional and/or national research committee and with the 1964 Helsinki declaration and its later amendments or comparable ethical standards. For this type of study formal consent is not required.

\section{References}

1. Ramkrishna J, Kan G, Reidy K, Ang C, Palma-Dias R. Non-tubal ectopic pregnancies: ultrasound diagnosis, management options and clinical outcomes. Ultrasound Obstet Gynecol 2015; 46 (Suppl. 1): $41 .$. https://doi.org/10.1002/uog.15070.

2. Panelli DM, Phillips $\mathrm{CH}$, Brady PC. Incidence, diagnosis and management of tubal and nontubal ectopic pregnancies: a review. Fertil Res Pract 2015; 1: 15. https://doi.org/10.1186/s40738-015-0008-z.

3. Parker VL, Srinivas M. Non-tubal ectopic pregnancy. Arch Gynecol Obstet 2016; 294(1): 19-27. https://doi.org/10.1007/s00404-016-4069-y.

4. Barnhart KT. Ectopic pregnancy. N Engl J Med 2009; 361(4): 379-387. https://doi.org/10.1056/NEJMcp0810384.

5. Jurkovic D. Cesarean scar pregnancy and placenta accrete. Ultrasound Obstet Gynecol 2014; 43(4): 361-362. https://doi.org/10.1002/uog.13346. 
6. Timor-Tritsch IE, Monteagudo A, Cali G, Vintzileos A, Viscarello R, AlKhan $A$, et al. Cesarean scar pregnancy is a precursor of morbidly adherent placenta. Ultrasound Obstet Gynecol 2014; 44(3): 346-353. https://doi.org/10.1002/uog.13426.

7. Gun M, Mavrogiorgis M. Cervical ectopic pregnancy: a case report and literature review. Ultrasound Obstet Gynecol 2002; 19(3): 297-301. https://doi.org/10.1046/j.1469-0705.2002.00559.x.

8. Shahraki AD, Khani B, Mohammadizadeh F, Hashemi L. Cervico-isthmic pregnancy is a potentially dangerous ectopic pregnancy. J Res Med Sci 2014; 19(1): 85-86. https://www.ncbi.nlm.nih.gov/pubmed/24672575

9. Giampaolino P, De Rosa N, Morra I, Bertrando A, Di Spiezio Sardo A, Zizolfi B, et al. Management of Cesarean Scar Pregnancy: A SingleInstitution Retrospective Review. Biomed Res Int 2018; 2018: 6486407. https://doi.org/10.1155/2018/6486407.

10. Jurkovic D. Caesarean section scar ectopic pregnancy: a new problem or new name for an old one? Australas J Ultrasound Med 2009; 12(1): 22-23. https://doi.org/10.1002/j.2205-0140.2009.tb00002.x.

11. Osborn DA., Williams TR., Craig BM., Cesarean Scar Pregnancy. Sonographic and Magnetic Resonance Imaging Findings, Complications, and Treatment. J Ultrasound Med 2012; 31(9): 14491456. https://www.ncbi.nlm.nih.gov/pubmed/22922626.

12. Timor-Tritsch IE, Monteagudo A. Unforeseen consequences of the increasing rate of cesarean deliveries: early placenta accreta and cesarean scar pregnancy. A review. Am J Obstet Gynecol 2012; 207(1): 14-29. https://doi.org/10.1016/j.ajog.2012.03.007.

13. Zosmer N, Fuller J, Shaikh H, Johns J, Ross JA. Natural history of early first-trimester pregnancies implanted in Cesarean scars. Ultrasound Obstet Gynecol 2015; 46: 367-375. https://doi.org/10.1002/uog.14775.

14. Timor-Tritsch IE, Monteagudo A, Cali G, El Refaey H, Kaelin Agten A, Arslan AA. Easy sonographic differential diagnosis between intrauterine pregnancy and cesarean delivery scar pregnancy in the early first trimester. Am J Obstet Gynecol 2016; 215(2): 225. e1-7. https://doi.org/10.1016/j.ajog.2016.02.028.

15. Jurkovic D, Mavrelos D. Catch me if you scan: ultrasound diagnosis of ectopic pregnancy. Ultrasound Obstet Gynecol 2007; 30: 1-7. https://doi.org/10.1002/uog.4077.

16. Tsai SW, Huang KH, Ou YC, Hsu TY, Wang CB, Chang MS, et al. Lowlying-implantation ectopic pregnancy: a cluster of cesarean scar, cervico-isthmus, and cervical ectopic pregnancies in the first trimester. Taiwan J Obstet Gynecol 2013; 52(4): 505-511. https://doi.org/10.1016/j.tjog.2013.10.009.

17. Bari S, Ara G, Nessa K. Pregnancy located below the internal os cervical and caesarean scar ectopic. Journal of Enam Medical College 2015; 5 (2): 118-121. https://doi.org/10.3329/jemc.v5i2.23386.

18. Litwicka K, Greco E. Caesarean scar pregnancy: a review of management options. Curr Opin Obstet Gynecol 2013; 25(6): 456-461. https://doi.org/10.1097/GCO.0000000000000023.

19. Harb HM, Knight M, Bottomley C, Overton C, Tobias A, Gallos ID, et al. Caesarean scar pregnancy in the UK: a national cohort study. BJOG 2018; 125(13): 1663-1670. https://doi.org/10.1111/1471-0528.15255.

20. Jabeen K, Karuppaswamy J. Non-surgical management of caesarean scar ectopic pregnancy - a five-year experience. J Obstet Gynaecol 2018; 38(8):1121-1127. https://doi.org/10.1080/01443615.2018.1451986.

21. Monteagudo A, Romero JA, Timor-Tritsch IE. Pregnancy in an Abnormal Location. Clin Obstet Gynecol 2017; 60(3): 586-595. https://doi.org/10.1097/GRF.0000000000000306.

22. Weichert A, Thomas A, Henrich W, Köhler C, Dudenhausen JW, Kalache KD. Cervico-isthmic pregnancy with cervical placenta accrete. Case Rep Perinat Med 2012; 1(1-2): 11-14. https://doi.org/10.1515/crpm2011-0006.

23. Honda T, Hasegawa M, Nakahori T, Maeda A, Sai R, Takata H, et al. Perinatal management of cervicoisthmic pregnancy. J Obstet Gynaecol
Res 2005; 31(4): 332-336. https://doi.org/10.1111/j.14470756.2005.00297.x.

24. Sakai A, Fujita $Y$, Yumoto $Y$, Fukushima $K$, Kobayashi $H$, Wake $N$. Successful management of cervico-isthmic pregnancy delivered at term. J Obstet Gynaecol Res 2013; 39(1): 371-374. https://doi.org/10.1111/j.1447-0756.2012.01967.x.

25. Timor-Tritsch IE, Khatib N, Monteagudo A, Ramos J, Berg R, Kovács S. Cesarean scar pregnancies: experience of 60 cases. J Ultrasound Med 2015; 34(4): 601-610. https://doi.org/10.7863/ultra.34.4.601.

26. Cali G, Forlani F, Timor-Trisch IE, Palacios-Jaraquemada J, Minneci G, D'Antonio F. Natural history of Caesarean scar pregnancy on prenatal ultrasound: the crossover sign. Ultrasound Obstet Gynecol 2017; 50(1): 100-104. https://doi.org/10.1002/uog.16216.

27. Ash A, Smith A, Maxwell D. Cesarean Scar Pregnancy. RCOG 2007, 114(3): 253-263. https://doi.org/10.1111/j.1471-0528.2006.01237.x.

28. Comstock $\mathrm{CH}$, Bronsteen RA. The antenatal diagnosis of placenta accreta. BJOG 2014; 121(2): 171-181. https://doi.org/10.1111/1471 0528.12557.

29. Timor-Tritsch IE, Monteagudo A, Bennett TA, Foley C, Ramos J, Kaelin Agten A. A new minimally invasive treatment for cesarean scar pregnancy and cervical pregnancy. Am J Obstet Gynecol 2016; 215(3): 351. e1-e8. https://doi.org/10.1016/j.ajog.2016.03.010.

\section{Authors:}

Tatiana B. Makukhina - MD, PhD, Associate Professor, Gynaecology and Perinatology Department for Postgraduate Education, Kuban State Medical University, Krasnodar, Russia. https://orcid.org/0000-0003-0536-4500.

Viktoriia V. Makukhina - Student, General Medicine Faculty, Kuban State Medical University, Krasnodar, Russia https://orcid.org/0000-0002-6238309X. 